\title{
ESTATÍSTICA PARA OS ANOS INICIAIS DO ENSINO FUNDAMENTAL
}

\author{
Marcelo Bergamini Campos ${ }^{1}$
}

CAZORLA, I. M.; MAGINA, S. M. P.; FERREIRA, V. G. G.; GUIMARÃES, G. L. (org.). Estatística para os anos iniciais do ensino fundamental. Brasília: Sociedade Brasileira de Educação Matemática - SBEM, 2017. (Biblioteca do Educador, Coleção SBEM, 9, E-book.)

A obra Estatística para os anos iniciais do ensino fundamental, fruto de um projeto de intercâmbio nacional financiado pela Coordenação de Aperfeiçoamento de Pessoal de Nível Superior (CAPES), é uma publicação da Sociedade Brasileira de Educação Matemática disponibilizada no formato $e-b_{o o o}{ }^{2}$. Trata-se de um trabalho que proporciona ao leitor importantes considerações relativas ao trabalho com a Estatística que envolvem a prática em sala de aula, informações conceituais e discussões teóricas. As autoras, através da abordagem do tema, discutem a possibilidade de contribuir com a formação de cidadãos críticos e conscientes e fomentar o desenvolvimento do pensamento científico de estudantes.

As organizadoras da obra têm vasta experiência em docência, especificamente na formação de professores, e importantes pesquisas desenvolvidas. Irene Maurício Cazorla, graduada e mestra em Estatística, é pós-doutora em Educação Matemática pela Pontifícia Universidade Católica de São Paulo (PUC-SP); Sandra Maria Pinto Magina, psicóloga, é pós-doutora pela Universidade de Lisboa. Elas atuam no mestrado em Educação Matemática da Universidade Estadual de Santa Cruz (UESC) em Ilhéus, na Bahia. Veronica Gitirana Gomes Ferreira, bacharela e mestra em Matemática, é doutora em Educação Matemática pela Universidade de Londres; Gilda Lisbôa Guimarães é pedagoga, além de mestra e doutora em Psicologia Cognitiva e pós-doutora pelas universidades de Burgos, na Espanha, e Laval, no Canadá. Ambas são professoras do curso de Pós-Graduação em Educação Matemática e Tecnologia da Universidade Federal de Pernambuco. É possível constatar que a formação diversificada das autoras,

1 Mestre em Educação Matemática pela Universidade Federal de Juiz de Fora (UFJF). Professor da Escola Municipal Sebastião Francisco do Vale, em Barbacena, Minas Gerais.

E-mail: marcelo.bergamini@hotmail.com

2 Disponível em: <http://www.sbembrasil.org.br/sbembrasil/index.php/publicacoes/colecao-sbem>. Acesso em: 7 jan. 2018. 
ao integrarem seus campos de conhecimentos, permite apresentar uma consistente obra que traz importantes contribuições sobre o assunto.

A introdução possibilita ao leitor ter um panorama geral da proposta defendida pelas autoras, que esclarecem a intenção de trazer subsídios para um profícuo trabalho com Estatística na formação inicial de crianças. Elas explicitam a perspectiva de contribuírem com a ampliação das competências do professor em três dimensões: "a dos conceitos relacionados à Estatística; a da organização de situações didáticas; e a da compreensão do desenvolvimento da aprendizagem dos conceitos estatísticos pelos alunos" (p. 10). É conveniente destacar que este objetivo é perseguido de forma muito bem articulada ao longo da obra, tomando como fio condutor a possibilidade de desenvolver projetos didáticos que podem ser utilizados em sala de aula. As situações abordadas fazem parte do dia a dia de alunos e professores, evidenciando a presença da Estatística no cotidiano.

No primeiro capítulo, intitulado "A Estatística nos anos iniciais do ensino fundamental”, as autoras explicitam suas concepções sobre conceitos centrais no trabalho com a Estatística no contexto escolar e defendem uma consistente abordagem do tema desde os anos iniciais. Apoiadas nos Parâmetros Curriculares Nacionais (PCN), elas observam que o trabalho com o assunto deve contribuir com a formação de cidadãos críticos, éticos e conscientes, destacando a possibilidade de estabelecer conexões com outras disciplinas e os Temas Transversais.

Diante da perspectiva da abordagem do tema concatenado aos moldes de uma pesquisa, as organizadoras da obra insistem que o seu tratamento não deve ficar restrito à coleta e à apresentação de dados. Em consonância com esta perspectiva, elas discutem as fases de uma investigação científica que é tomada como pilar para a construção da proposta apresentada nos capítulos seguintes.

No segundo capítulo, “A identificação do problema”, são delineadas as fases iniciais de uma investigação estatística, que envolvem a escolha do problema, a identificação das questões de pesquisa e o levantamento das hipóteses e das variáveis que serão analisadas.

A delimitação do problema pode surgir a partir de uma curiosidade manifestada pelas crianças. Segundo as autoras, o professor deve aproveitar esta oportunidade e fomentar o espírito investigador dos alunos, lembrando a importância de que todos estejam motivados na pesquisa, que deve ser interessante e desafiadora. No entanto, o docente precisa analisar a sua viabilidade e atentar-se para fatores como o tempo necessário e a adequação ao nível de escolaridade e às potencialidades didáticas. O leitor pode perceber a diversidade de circunstâncias que podem ser exploradas e as diferentes categorias de fenômenos observáveis.

As organizadoras afirmam que as crianças tendem a apresentar respostas a partir de suas crenças, que poderão se constituir em conclusões ou serem refutadas. A produção 
dessas hipóteses é vista como uma etapa fundamental da educação estatística, sendo importante que os alunos compreendam o fenômeno investigado e as variáveis que o influenciam.

No terceiro capítulo, intitulado "Coleta de dados”, são apresentados conceitos estatísticos e discutidos os procedimentos e as diferentes decisões que podem ser tomadas nos processos de coleta e classificação dos dados.

Ao demarcar a amostra a ser pesquisada é preciso atentar-se à quantidade de dados que serão suficientes para representar o fenômeno, considerando a execução e a operacionalização da investigação. As autoras alertam também sobre cuidados a serem tomados na definição dos sujeitos de pesquisa, na elaboração dos instrumentos para coleta de dados e na delimitação das variáveis que podem representar o fenômeno. Elas ratificam a importância da participação ativa dos estudantes nestas decisões, percebendo a representatividade das amostras, refletindo sobre as suas escolhas e as implicações nos resultados e atentando para que os objetivos da pesquisa sejam alcançados. Para isso, é fundamental que o professor tenha clareza sobre o processo e busque potencializar o desenvolvimento do pensamento estatístico dos estudantes.

No quarto capítulo, “Tratamento dos dados”, o foco é direcionado à discussão sobre a elaboração de tabelas e gráficos e aos conceitos de algumas medidas estatísticas. A apresentação destes instrumentos ocorre de forma muito bem articulada, conduzindo o leitor a uma reflexão sobre as potencialidades de cada um deles diante da busca de respostas à questão de pesquisa, possibilitando a identificação e a análise das informações propiciadas por cada representação.

A partir da construção de planilhas de dados, são explorados a elaboração de diferentes tipos de tabelas e os conceitos de frequência relativa e absoluta. O texto ressalta que o professor deve perceber que a leitura de uma tabela não é habilidade simples e intuitiva, mas demanda um trabalho sistematizado com os estudantes.

As autoras apresentam interessantes e criativas propostas de construções de diferentes tipos de gráficos e lembram as potencialidades destas representações na visualização dos dados. Elas apontam alguns erros que podem ser cometidos pelos alunos e orientam o professor sobre os cuidados a serem tomados e a necessidade de adequações levando em consideração o nível de escolaridade dos estudantes. Dedicam especial atenção à discussão do trabalho com escalas. Partindo da frequência unitária, abordam as escalas proporcionais pontuando que não se trata de uma construção trivial e sinalizam algumas dificuldades que as crianças podem encontrar. Mencionam ainda que a mídia pode apresentar gráficos com distorções nas escalas, alerta que reforça a importância do seu aprendizado para que os estudantes sejam leitores críticos de informações.

Com relação às medidas estatísticas, o foco não é direcionado apenas às estratégias de cálculo. O texto explora, de forma integrada, a compreensão e o uso de cada representação, apontando suas potencialidades na identificação das informações 
obtidas através de dados coletados. Na abordagem da média aritmética, são expostas interpretações equivocadas que os estudantes podem apresentar para valores encontrados principalmente nas situações em que são expressos por um número não inteiro. $\mathrm{O}$ trabalho com a mediana é articulado ao processo de ordenação que é explorado nos anos iniciais.

Iniciando uma discussão que é aprofundada no capítulo seguinte, quando o foco recai sobre a análise dos resultados, as autoras sinalizam a possibilidade de fazer um cruzamento a partir dos dados obtidos. Elas evidenciam que o professor precisa contribuir para que os estudantes desenvolvam uma compreensão integrada acerca de gráficos, tabelas e medidas estatísticas e, dessa forma, possam ampliar o entendimento sobre a natureza dos dados.

No quinto capítulo, intitulado "Interpretação dos resultados”, as organizadoras reforçam a premissa de que uma pesquisa não termina com a organização e o tratamento dos dados. Elas insistem na necessidade de retomar as questões que motivaram a investigação e verificar a validade das hipóteses, indicando ao leitor as potencialidades desta proposta ao desencadear reflexões a partir da análise dos dados organizados. São apresentadas também sugestões de relatórios para comunicar as conclusões e as respostas às questões da pesquisa que, conforme exemplificado no texto, podem entrar em conflito com as concepções prévias dos alunos.

No capítulo que encera a obra, intitulado "Pesquisa experimental: o jogo da memória”, as autoras sugerem uma situação a ser desenvolvida com crianças a partir do primeiro ano. Com base em dados hipotéticos, apresentam diferentes planilhas, tabelas e gráficos que podem ser construídos de acordo com relações entre variáveis, buscando analisar e responder à investigação. Elas também recorrem, de forma muito bem articulada, à análise de algumas medidas estatísticas.

O livro é complementado com alguns anexos. Nestes documentos são sinalizadas novas sugestões de projetos que podem ser desenvolvidos em sala de aula e aprofundadas discussões que permeiam a obra. Em alguns momentos, são apresentados estudos relacionados ao trabalho com a Estatística, o que traz importantes informações teóricas para o leitor.

Diante do exposto, é possível apontarmos a singularidade da obra na abordagem do ensino de Estatística e, para isso, destacamos dois motivos. Em primeiro lugar, as organizadoras estabelecem um recorte pertinente ao voltar as discussões exclusivamente para os anos iniciais, fase de escolarização que tem uma carência de estudos. Em segundo lugar, a abordagem do tema não fica restrita ao tratamento de dados, mas é associada a uma ótica investigativa, que busca contribuir com o desenvolvimento do pensamento científico dos estudantes.

Vale observar que esta perspectiva defendida pelas autoras imprime uma mudança no papel que vem sendo desempenhado pelo estudante no modelo de ensino tradicional, 
em que é percebido, quase sempre, como receptor e armazenador de conhecimentos. Na proposta apresentada, o aluno tem a oportunidade de assumir uma postura ativa, é convidado a elaborar questões, levantar hipóteses, refletir sobre escolhas e compreender as implicações, as vantagens e as desvantagens das decisões tomadas.

A leitura da obra permite apontar o tratamento limitado e incipiente que muitas vezes é conferido à Estatística não apenas nos anos iniciais, mas ao longo da Educação Básica. A proposta de trabalho que permeia o livro destaca a importância de desenvolver análises e reflexões a partir dos dados coletados, um importante aspecto no trabalho com a Estatística que, via de regra, é preterido no contexto escolar.

A linguagem usada pelas organizadoras é clara e consistente. A proposta de discutir os conceitos estatísticos articulados à apresentação de sugestões de projetos didáticos de caráter investigativo é extremamente profícua. Convém apenas apontar a necessidade de pequenos ajustes no texto como, por exemplo, na figura 50 e na planilha apresentada no quadro 10. No entanto, são questões pontuais insuficientes para ofuscar o brilho do trabalho.

Podemos inferir que a obra traz importantes contribuições para a formação inicial ou continuada de professores, o que permite destacar a relevância da sua leitura para os profissionais que atuam nos anos iniciais e também na matemática da educação básica. Pesquisadores do tema poderão encontrar consistentes considerações ou acessar outros trabalhos a partir das referências e das sugestões de leitura apontadas. Portanto, trata-se, de um livro que possibilita ao leitor desenvolver reflexões ampliadas sobre os conteúdos abordados e as estratégias didáticas, bem como os objetivos do ensino de Estatística.

Recebido em: 02/08/2018

Aprovado em: 27/03/2019 